\title{
Cinco siglos resistiendo: la marcha del 12 de octubre en Buenos Aires y Santiago de Chile como memoria colectiva cronotrópica y de reivindicación amerindia en Abya Yala
}

\author{
Five centuries resisting: The March of October 12 in Buenos Aires \\ and Santiago de Chile as collective chronotopic memory and Amerindian \\ revindication in Abya Yala \\ Pablo Mardones Charlone* \\ Instituto de Estudios Internacionales, Universidad Arturo Prat, Iquique, Chile \\ Francisca Fernández Droguett ${ }^{* *}$ \\ Escuela de Antropología, Universidad Academia de Humanismo Cristiano, \\ Santiago de Chile
}

Recibido: 23 de septiembre de 2016. Aceptado 28 de enero de 2017

\section{Resumen}

El 12 de octubre de 1492 es el día en el que según las crónicas Cristóbal Colón llegó al Caribe. Entonces, ¿Cómo llegó éste a constituirse en jornada de reflexión, protesta y reivindicación a través de una marcha anual que en 2016 cumplió 25 años de realización ininterrumpida en dos grandes urbes, Buenos Aires y Santiago, históricamente imaginadas como "blancas"? En ambas ciudades, las únicas donde se realiza esta marcha, son amerindios (tanto extranjeros como nacionales) quienes protagonizan la misma, siendo ésta conducida en clave festiva a través de la música y la danza. En este territorio alejado del Caribe, la fecha mágica de los quinientos años ha permitido cristalizar demandas amerindias históricas, generando, a través del símbolo de una efeméride, un

Doctor en Ciencias Antropológicas Universidad de Buenos Aires. Investigador asociado del Instituto de Estudios Internacionales (INTE) de la Universidad Arturo Prat. Correo electrónico: pmardones@alpacaproducciones. com.ar.

** Doctora en Estudios Americanos del Instituto de Estudios Avanzados de la Universidad de Santiago de Chile. Investigadora y docente de la escuela de Antropología de la Universidad Academia de Humanismo Cristiano. Correo electrónico: docentefernandez@gmail.com 
sentido de pertenencia común con el resto de la región. En este trabajo, describiendo su contexto, génesis e historia, y haciendo un análisis desde los usos políticos de la memoria a través de una lectura cronotrópica (donde un evento significativo del pasado adquiere relevancia en el presente para volverse significativo en el futuro), intentamos dar pistas y proponer algunas líneas sugerentes para comprender este hecho y sus repercusiones.

Palabras clave: amerindio, marcha conmemorativa, cronotrópica

\begin{abstract}
According to the chronicles of history, October 12th, 1492 is the day when Christopher Columbus arrived to the Caribbean. How then did this date become a day for reflection, protest and demand through an annual march that in 2016 completed 25 years without interruption in two of the largest cities in South America, Buenos Aires and Santiago? In both cities, which has historically been imagined as "white", indigenous communities (both domestic and foreign) are the organizers of the march, which is driven by the festive contributions of indigenous musicians and dancers. In a place so far from the Caribbean, the date of the $500^{\text {th }}$ anniversary of Columbus' arrival has allowed for the crystallization of indigenous demands and generated a common sense of belonging with the rest of the region. In this paper, we describe the context, genesis and history of the march and provide an analysis of the political uses of memory through a chronotropic reading (where a significant event from the past acquires relevance in the present and becomes significant in the future) in order to propose several strands of interpretation for the march's emergence and its repercussions.
\end{abstract}

Key words: indigenous, commemorative march, chronotropy 


\section{Introducción}

En las únicas ciudades de América latina donde se lleva a cabo una marcha permanente ${ }^{1}$ que rememora la fecha del 12 de octubre, es en Buenos Aires y Santiago de Chile. Ambas activas desde 1991, el 2016 cumplieron 25 años de realización ininterrumpida ${ }^{2}$. En el resto del continente se han realizado algunos años diversas movilizaciones asociadas a la fecha, pero no de forma permanente.

A nuestro modo de ver, la instalación de esta marcha en las capitales de Argentina y Chile ha sido producto histórico de la cristalización de un proceso, en el que comunidades y organizaciones amerindias, y otras entidades sociales afines, se apropiaron simbólicamente de esta fecha en particular.

En la redacción del presente artículo, la elección de la terminología más adecuada para definir a los diferentes pueblos de la actual región latinoamericana con vínculos preexistentes a la conquista europea, ha sido una tarea compleja. Consensuando que lo más adecuado es utilizar las propias denominaciones genéricas (Albó, 2008), como aymaras, qollas, quechuas o mapuche, el desafío radica cuando se busca hablar de ellos y ellas en conjunto.

Por un lado, resistimos el título indio, ya que el mismo fue establecido por una confusión histórica además de poseer una carga racista arrastrada desde la conquista y colonia. Por otro, objetamos los calificativos nativo, originario o indígena debido a que todos remiten a la condición de origen, concepción que invisibiliza las dinámicas migratorias históricas de los pueblos de América. Asimismo, como arguye Silvia Rivera Cusicanqui (2013), estas terminologías sitúan a estos pueblos en una especie de pureza precolonial que no es coetánea, emplazándola lejos del presente. Basarse en el origen es situarse en un lugar fuera del tiempo asentado en lo inmutable y no en la contemporaneidad, que es justamente el contexto temporal que aquí buscamos resaltar.

El debate a partir de estas ideas, generó el rescate de dos términos. Por un lado el de amerindio, el cual pese a no lograr escapar completamente de una condición etnocéntrica, sintetiza las condicionantes históricas de los habitantes del continente desde la llegada de Colón (América - indio), con una referencia que se presenta, justamente, como contraria

1 Por marcha, comprendemos cualquier tipo de manifestación política que implique necesariamente un desplazamiento. Y por marcha conmemorativa, cualquier marcha que se realice anualmente.

2 En el caso de Buenos Aires, ya había manifestaciones desde la década de los ochenta del siglo XX, pero las mismas no eran masivas. 
a la de origen. Y por otro, el de pueblos del Abya Yala, vocablo propio del pueblo kuna (sur de Panamá, norte de Colombia) traducido como continente rodeado de mar, tierra madura, tierra viva o tierra en florecimiento. El mismo, desde hace un tiempo ha comenzado a utilizarse para referirse a América latina, criticando la concepción de latino de ésta. Prevaleciendo los nombres propios de cada pueblo y los utilizados por las mismas organizaciones, instituciones o datos censales, serán estos términos, amerindio y pueblos del Abya Yala, los que utilizaremos a la hora de hacer análisis o enfoques globales.

En el proceso de apropiación simbólica del 12 de octubre se fueron condensando reflexiones, protestas y reivindicaciones sobre la base de un movimiento de contrafestejo y en repudio a la consolidación de esta fecha mágica de los quinientos años (Yañez Barnuevo, 1992). Se trata de una efeméride que fue "orquestada" desde España durante distintos periodos del siglo XX, a partir de la validación de su figura imaginada como "madre patria". Esto podría explicar porqué tanto en Buenos Aires como en Santiago, ciudades alejadas del Caribe, la marcha conmemorativa se lleva a cabo el día que el conquistador Cristóbal Colón habría llegado a la isla Guanahani, actualmente Las Bahamas. Desde 1992 en adelante, para un sector social relevante en la región, esta fecha se fue paulatinamente transformado en símbolo de una crítica global a las dinámicas de hispanización impuestas en el continente desde la conquista.

Según Alejandro Isla (2003), las narrativas de la memoria enfatizan ciertos acontecimientos convirtiéndolos en conmemoraciones, mientras otros son relegados al olvido. En este caso, el evento histórico de la llegada de Colón se posicionó como el hito a conmemorar.

En este contexto, será la construcción de una memoria colectiva la que consolidará un discurso supraétnico (Mires, 1992) de la identidad amerindia como condición compartida de subalternidad de diversos pueblos frente a una entidad colonial. Supraétnico comprendido como la generación de un elemento articulatorio bajo la figura de pueblos que comparten una historia común de colonización, y que a su vez, y justamente por ello, han desplegado una serie de demandas conjuntas. Esto se traduce en la reivindicación como colectividad de una sucesión de eventos que, en palabras de Isla (2003), son leídos cronotrópicamente. Es decir, un evento significativo del pasado que adquiere relevancia en el presente para volverse significativo en el futuro. Según este autor, el caso de conmemoraciones como la del 12 de octubre, se presentan como escenarios propicios para la rememoración histórica de diversos pueblos.

Considerando lo expuesto, este artículo tiene por objetivo caracterizar y reflexionar sobre las dinámicas conmemorativas del 12 de octubre en las ciudades de Buenos Aires 
y Santiago, analizando los repertorios culturales (Santos, 2012) que comparten ambas instancias y en las que se diferencian. Entendemos por repertorios culturales el conjunto de prácticas y discursos desde donde los sujetos se sitúan a través de su experiencia de vida, actuando como marcos de referencia para los contextos de acción e interacción social. La idea es proponer lecturas que puedan aportar a comprender por qué en estas ciudades la lectura cronotrópica del 12 de octubre se generó en formato de marcha permanente.

Estas dos metrópolis son las capitales de dos de los estados-naciones latinoamericanos donde históricamente se ha invisibilizado lo amerindio. Los imaginarios sociales internos y externos buscaron instalar a lo largo del tiempo la falaz idea de que estas ciudades eran predominantemente "blancas". Mientras Buenos Aires fue imaginado históricamente como un enclave europeo (Grimson, 2005), en Santiago se consolidó un proceso de blanqueamiento imaginado (Bengoa, 2007).

Esta condición se evidencia en el re-nombramiento que tuviera en el último tiempo este día en ambos países desde el marco legal, "Día del Encuentro de Dos Mundos" en Chile ${ }^{3}$ (2000) y "Día del Respeto a la Diversidad Cultural" en Argentina ${ }^{4}$ (2010). A diferencia de otros países de la región, como Bolivia, Nicaragua o Venezuela ${ }^{5}$, la condición de "lo amerindio" se mantuvo ajena en su designación.

En este contexto, a modo de hipótesis esgrimimos que es justamente dicha condición de ciudades "blancas", y la consiguiente oposición de una fecha orquestada desde España, la que generó en ambos casos la necesidad de crear una plataforma de lucha conjunta. En esta dinámica operó una lectura cronotrópica que reconfiguró un evento significativo del pasado -distanciado de la historia próxima del conosur- para consolidarse en el presente en clave festiva a través de la danza y la música, constituyéndose en la principal expresión política amerindia de Buenos Aires y Santiago.

Por su parte, la marcha del 12 de octubre se erige en la principal herramienta de rechazo al imaginario de "descubrimiento" y de convicción europeicista, ideas cristalizadas en el año 1992 en Argentina frente a la realización de la Expo-América, y en Chile por la controversial participación de un iceberg como símbolo del país en la Exposición Universal de Sevilla. Sobre todo, este día constituye un hito en la reivindicación de la condición

\footnotetext{
Ley 19.668, pasando al lunes más cercano al 12 de octubre si esta fecha cae entre martes y viernes.

4 Decreto de Necesidad y Urgencia 1564/2010.

5 "Día de la resistencia indígena" en Venezuela (2002) y Nicaragua (2005) y "Día de la Descolonización" en Bolivia (2011).
} 
amerindia de dos capitales que han sido bastión de las políticas de blanqueamiento en la región, -a pesar de contar con una relevante presencia de población amerindia. En este proceso, varias organizaciones no amerindias, se han posicionado afines a sus demandas y reivindicaciones.

Lo revelador de la consolidación de esta marcha en esta fecha, es que el movimiento de rechazo desde organizaciones amerindias junto a otras de la sociedad civil, habría surgido no tanto a partir de dinámicas locales sino más bien en repudio a su instauración en España. Será el primer capítulo, titulado "La orquestación Española y la resistencia latinoamericana", el encargado de dar cuenta de dichos sucesos y su respectiva reacción.

En Buenos Aires esta marcha manifiesta el carácter político del reconocimiento, sobre todo de migrantes del norte del país así como de los países vecinos de los Andes centrales. En Santiago en cambio, los principales protagonistas son el pueblo mapuche, personas afines a sus demandas y colectividades de danza y música que reivindican sus condición de andinos ${ }^{6}$, sin ser necesariamente aymaras o quechuas. Siendo su reivindicación como tales, construida sobre el hecho de habitar en los pies de la cordillera de Los Andes y en una territorialidad hoy reconocida como parte de lo que fue el Tawantinsuyu. Será el segundo capítulo, "Buenos Aires: el enclave europeo como resistente espacio de contrafestejo" y el tercero, "Santiago: desde la política del blanqueamiento a la configuración identitaria amerindia", donde se analizarán cómo ciertas causas y circunstancias -algunas históricas, otras coyunturales- influyeron en la consolidación en ambas ciudades de este evento. Posteriormente, en un cuarto capítulo, el cual hemos llamado "25 años marchando. Análisis comparativo entre Buenos Aires y Santiago", cotejamos similitudes -en las cuales descansa nuestra hipótesis y principal argumento- y diferencias de esta marcha en ambas ciudades. Finalmente, en un capítulo de cierre, sintetizamos las ideas fuerza y hacemos algunos comentarios complementarios con el fin de condensar nuestro punto de vista.

Como metodología de trabajo, además de una sistematización bibliográfica en torno a las principales categorías analíticas aquí desarrolladas, se llevó a cabo una investigación comparativa mediante la auto-observación de los investigadores, en tanto partícipes en su condición de músico (para el caso argentino) y de danzante (para el chileno), así como la realización de entrevistas abiertas a manifestantes, músicos, danzantes y dirigentes amerindios.

6 Referiremos en el caso de Santiago a "andinos" para hablar de expresiones propias de los denominados Andes centrales, ya que es el término que ha tomado protagonismo en las últimas décadas. Pese a que el mismo fue creado por antropólogos europeos y norteamericanos durante el siglo XX. 
El hecho de ser danzante y músico, y el involucramiento en los proyectos políticos que esto motivó, nos exigieron reflexionar sobre la tensión entre ser investigador social y sujeto parte de los procesos a ser analizados (Caicedo, 2003). Al identificarnos como danzantes y músicos, al igual que gran parte del universo que participa en esta marcha en ambos países, nos encontramos con el desafío y el potencial metodológico de desarrollar un trabajo desde la antropología colaborativa. De esta forma, tanto en la producción de la información recopilada a lo largo de más de una década así como en su posterior análisis, hemos buscando comprometernos en generar mecanismos de desmonopolización de la mirada, relativizando la autoridad etnográfica (Rappaport, 2007).

\section{I) La orquestación Española y la resistencia latinoamericana}

El 12 de octubre fue orquestado de forma cronotrópica por España a lo largo del siglo XX y convertido en el día de la raza (Rodríguez-San Pedro, 1913), luego de la hispanidad (Alfonso XIII, 1918) y finalmente en fiesta nacional de España (González, 1987), transformándose en la efeméride que simboliza actualmente a España como Estadonación.

Fue en 1982, con la llegada al poder de Felipe González ${ }^{7}$, cuando se consolidó la última etapa de esta orquestación. En este periodo comenzó el diseño de una nueva relación internacional donde se asumía que América latina tendría un papel clave (Yáñez Barnuevo, 1992). Así, en 1987, a un año de haber entrado en la Comunidad Económica Europea (CEE), se nombró al 12 de octubre como fiesta nacional de España, dando inicio en 1991, con la cumbre de Guadalajara, a la política de las cumbres iberoamericanas.

En síntesis, las autoridades españolas institucionalizaron el 12 de octubre como símbolo de la hispanidad, de culto de la patria, encarnando el rito de pasaje de corona a república mediante la dominación de América.

El primer país en institucionalizar esta efeméride en América latina, fue la Argentina (Zacarías de Vizcarra, 1944) en 1917, cuando el presidente Hipólito Irigoyen declaró este

7 Los antecedentes de la orquestación española se remontan a 1976, con la visita del rey de España a América latina. En aquella ocasión, Juan Carlos I habría gestado la idea de realizar distintas cumbres en vista al quinto centenario.(Drago, 1992). 
día como festivo. La iniciativa de Argentina encontró eco en América latina, donde los demás países, vía ley o decreto, fueron gradualmente sumándose a esta iniciativa.

La construcción de una iberoamericanidad como comunidad imaginada (Anderson, 1993) tuvo complicidad en ambos lados del Atlántico. Ideas como ex colonias americanas (Bunge, 1992) para referirse a los países de la región; la presunción que si la región no se unía a España y Portugal se correría el riesgo de una recolonización por los EEUU (Bunge, 1992), y la exaltación respecto a la posición geo-cultural de la península ibérica como pontífice -hacedora de puentes- entre Occidente y Oriente, y entre el Norte y el Sur (Gala, 1992), concebían que dicha alianza le permitiría a la región salir de una situación desfavorable (Piñeiro, 1992).

Como reacción a lo que aquí hemos denominado orquestación española, en América latina el 12 de octubre se configuró en una fecha de manifestación y de repudio tanto de la percepción de descubrimiento como a la dinámica de negación de lo amerindio.

La fecha-símbolo se introdujo en algunas agendas políticas y de ciertos medios de comunicación, donde se destacó su relevancia como hito histórico del descubrimiento o de encuentro. Pero esta vuelta al evento histórico de la colonización también se constituyó como locus de nuevas lecturas. Estos acontecimientos generaron una apropiación simbólica y, en consecuencia, un periodo signado por acciones reivindicativas.

Así, en el contexto de la "primermundialización" española, la conmemoración de los quinientos años abrió una nueva arena global de disputas de sentidos. En este proceso se gestó el contra-festejo como una posición política con alcances locales, nacionales, regionales e internacionales. En esta dirección, la institucionalización del 12 de octubre -que antes celebraba una matriz de idioma-religión-mestizaje-cultura entre España y América latina- dio lugar ahora a un movimiento de rechazo a dicha orquestación, donde la condición de víctimas posicionó a los pueblos amerindios de la región, como una fuerza política homogénea.

Paralelamente a los sucesos acontecidos en España, los pueblos y comunidades amerindias de América se organizaron para conmemorar los quinientos años de Resistencia Indígena, "espacio ideal para que se pronunciaran aquellos que hasta entonces habían permanecido silenciados" (Bengoa, 2000, p. 21). Con el pasar del tiempo, y en la medida en que los movimientos sociales indígenas fueron entramando textos públicos y autorizando reclamos de justicia y reparación histórica, no sólo hicieron emerger en el campo de 
visibilidad una nueva subjetividad política, sino que también fueron contando con un apoyo progresivo de la sociedad más amplia.

Argentina y Chile no fueron ajenos a ese proceso, y ambos desde sus capitales, imaginadas como "blancas", conformaron desde 1991 una marcha conmemorativa sobresaliente en el presente.

\section{II) Buenos Aires: el enclave europeo como resistente espacio de contrafestejo}

Como anteriormente se señala, Argentina fue el primer país de América latina en instaurar como día festivo el 12 de octubre (1917). En el 2004, la diputada Alicia Castro presentó un proyecto para que el 13 de octubre se declarara como el Día de la Resistencia Indígena y Popular, mientras que su par Carlos Tinnirello presentó otra iniciativa para que se derogara el festejo del día 12 y se declarara al 11 como Día de la Reivindicación de los Pueblos Originarios. Finalmente, sin una connotación en lo amerindio, en el 2009 prosperó el 12 de octubre como Día del Respeto a la Diversidad Cultural.

Actualmente en Buenos Aires este día se ha convertido en una marcha emblemática, en la cual sus protagonistas son principalmente migrantes internos que se autoadscriben como kollas o qollas, e internacionales, como aymaras y quechuas, así como hijos y nietos de éstos. Además, en menor medida, de otros pueblos amerindios como diaguitas, guaraníes, qom, mapuches y wichís radicados en la ciudad. Con el tiempo, se fue adhiriendo un creciente grupo de porteños y bonaerenses ${ }^{8}$, convocados, en enorme proporción, como intérpretes del instrumento autóctono siku, entre otros simpatizantes $\mathrm{y}$ adherentes.

El repudio a los 500 años de conquista en Buenos Aires, se enmarca en diversos procesos previos de auto reconocimiento como amerindios. Como espacios primordiales en este devenir, destacan la Asociación Indígena de la República Argentina (A.I.R.A.) creada en 1978, y el Centro Kolla en 1980 (Barragán, 2003), ambos fundados por kollas jujeños que reivindican el legado amerindio a través de la expresión musical. Con el tiempo, el Centro Kolla se fue fortaleciendo como espacio de reflexión y organización, siendo durante la

8 Porteño es el gentilicio de los oriundos de la Ciudad Autónoma de Buenos Aires, mientras que bonaerense de aquellos nacidos en la Provincia de Buenos Aires. 
década de los ochenta, junto con A.I.R.A., parte de los principales referentes del tema amerindio en la ciudad.

Cabe destacar que la auto-adscripción de cierto sector de los inmigrantes bolivianos, y en menor medida peruanos, como aymaras y quechuas, pasó en gran medida por el reconocimiento de los qollas argentinos, quienes fueron los pioneros en la lucha por el reconocimiento amerindio (Villanueva, 2014). El hecho de ser extranjeros, particularmente de países vecinos, los situaba en una situación de discriminación, tanto legal como social y cultural, y su auto-reconocimiento como amerindios los ubicaba en una doble situación de discriminación.

Según los testimonios recogidos, fueron varias las instancias que, antes del año 1992, permitieron el surgimiento del 12 de octubre como fecha conmemorativa.

Según Villanueva (2014), la idea de la marcha se comenzó a gestar desde la década de los ochenta del siglo XX.

Se hablaba de diversas acciones, especialmente de las ceremonias. La pachamama era muy conocida. Después se empezó a generar, no me acuerdo precisamente el año, una idea de gestar la marcha, pero que nos íbamos preparando para lo que eran los quinientos años eso era cierto, nos veníamos preparando con intencionalidad. Ya en los ochenta, hacíamos juntadas incipientes (Villanueva, 2014, p.5).

Por su parte, tanto Paris Barrera (2016) como Luis Romero (2016) relatan que ya desde la década del ochenta varios compañeros se movilizaban.

Esperaban que terminen los desfiles de los españoles [...] y después arrancaban ellos con los suyo. La del ' 91 y la del ' 92 fue más grande pero antes ellos ya se juntaban en las escaleras del monumento. Cosas de antaño, eran ocho o nueve" (Barrera, 2016, p. 1).

No era una marcha masiva, pero si había movilización desde el comienzo de la democracia" (Romero, 2016, p. 2).

Asimismo, Fernando Barragán (2014), músico sikuri, comenta: Los sikuris ya veníamos reuniéndonos en la década del ochenta, pero fue en 1991 y, claro, en 1992, cuando nos convocamos en forma masiva a través de la agrupación músicos independientes (Barragán, 2004, p.18). 
Según Diana Lenton (2013), en la década de los ochenta comenzaron a realizarse algunas actividades y a abrirse espacios en los cuales se generó un proceso de reflexión respecto al tema de los quinientos años. Por otra parte, surgió en el imaginario de quienes se estaban manifestando en contra un evento que potenció el rechazo, la Expo-América '92, erigida por el entonces gobierno de Carlos Menem, en lo que posteriormente se convertiría en el barrio de Puerto Madero. Fue una muestra sobre el "descubrimiento" de América, creada a semejanza de la Exposición Universal de Sevilla 1992, que tenía como lema La Era de los Descubrimientos', la que condensó el repudio.

La Expo '92 pretendía un vínculo modernizador con la madre patria, viendo a lo indio como lo arcaico, como parte del pasado. Este ideal también tuvo eco en una izquierda de élite anti-amerindia que promulgaba con fuerza contra el atavismo amerindio. Uno de los más claros ejemplos es el libro El asedio a la modernidad de Juan José Sebreli (1991).

Las marchas del '91 y '92 se llevaron a cabo en la Avenida 9 de Julio, trasladándose en '93, y hasta el presente, a la Plaza de los Dos Congresos. Desde el comienzo tuvieron gran protagonismo los intérpretes de música autóctona, particularmente los sikuris, en su mayoría inmigrantes del noroeste argentino y de Bolivia, o hijos de éstos nacidos en Buenos Aires.

En 1992, los sikuris se organizaron en una gran banda de más de 180 tocadores, acompañada por una multitud de charangos y percusiones. La formación de músicos contaba con una fila central de bombos a modo de columna vertebral y un perímetro realizado con una gigantesca pancarta rodeando a la escuadra de tocadores, flanqueada con decenas de teas y antorchas. Entre la gran banda y el público en general, se logró conformar una multitudinaria manifestación que superó las nueve mil personas (Barragán y Mardones, 2012). Además de los sikuris participaron algunas agrupaciones políticas, centros culturales y talleres, así como espacios de investigación y movimientos de Derechos Humanos.

Con el tiempo, una de las características que la marcha ha ido adquiriendo es la diversificación de los participantes. En el siglo XXI se han ido incorporando nuevas organizaciones amerindias, así como un número cada vez mayor de no amerindios, muchos de ellos músicos sikuris.

9 http://www.expo92.es/laexpo/index.php?seccion=cifras 
De acuerdo con algunos testimonios, primaba -condición que perdura hasta la actualidadun ambiente de rechazo hacia las posiciones partidistas, así como una valorización del lugar social -aparentemente independiente- de los músicos:

Nosotros nos juntábamos sin intencionalidad política partidista, sin querer participar de partidos políticos. Si bien eso ocurrió, varios hermanos encontraron un lugarcito en un partido político y se quedaron. Pero en su mayoría, no estaba esa intencionalidad. Estábamos resistiendo, estábamos cantando, estábamos declarando que éramos originarios (Villanueva, 2014, p. 9).

Con esta elección, y tal como lo expresa Villanueva, el mensaje central residía en mostrar que se "estaba resistiendo, cantando, declarando que éramos originarios". Es decir, volver visible un colectivo donde la música fue el lenguaje de una emergente subjetividad política, como un lugar social diferenciado de otras manifestaciones de protesta. De esta forma, el 12 de octubre de 1992 se convirtió en un proceso creciente de reivindicación, en un hito que simbolizaría un cambio.

Según Villanueva (2014), el 12 de octubre del ' 92 fue como una puerta para darle apertura a esto, a lo que estamos hoy.

Se trató de un proceso que ha ido creciendo, y han quedado hermanos hasta el día de hoy trabajando en la coordinación de esta marcha [...] luego distintos actores comenzaron a generar nuestros propios espacios. [...] El objetivo, yo creo que se cumplió, porque el 12 funcionó como un disparador para que se generaran muchas iniciativas (Villanueva, 2014, p. 3).

Desde hace un tiempo, antes de la marcha se monta un estrado frente al Congreso Nacional, sobre la avenida Callao, donde tocan distintas agrupaciones (con guitarra, charango, siku, quena, entre otros instrumentos). Algunos de estos músicos luego se suman a la marcha como sikuris. Esta instancia sirve como tiempo para convocar a los marchantes.

Posteriormente comienza la marcha. La misma va desde el congreso por Avenida Callao en dirección a Corrientes, luego hasta el Obelisco para tomar la calle Cerrito y finalmente retomar la Avenida de Mayo hasta el congreso nuevamente. 
Una de las particularidades de la marcha del 12 de octubre en Buenos Aires, es que la misma se presenta como lugar para un reclamo unificador, pero donde no suelen aparecer demandas políticas coyunturales, las cuales han tendido a tener su propio espacio. Se reivindica la lucha amerindia en general, con la participación de distintas pertenencias y con un discurso reivindicativo basado en la diversidad de pueblos con propósitos políticos similares en un territorio que históricamente ha sido asumido con una representación amerindia poco significativa.

Uno de los símbolos de este sentido unificador, es la presencia de una canción sikuri que se interpreta tanto este día como en prácticamente todas las instancias sociales y políticas amerindias en la ciudad de Buenos Aires, titulada "Cinco siglos". La letra fue escrita por el boliviano Daniel "Lobo" Paz en 1992 en Buenos Aires. La melodía es una obra inédita del siglo XVIII del pueblo de Italaque, de la región de Escoma, Provincia Camacho, Departamento de La Paz, Bolivia (Barragán y Mardones, 2012). Esta canción se fue constituyendo en el himno de los pueblos amerindios de Buenos Aires. Versa así:

"Cinco Siglos resistiendo, cinco siglos de coraje, manteniendo siempre la esencia (bis), es tu esencia, es semilla, está adentro nuestro por siempre (bis), se hace vida con el sol (momento en que todos levantan las brazos) y en la pachamama florece (bis)".

Se trata de palabras de reivindicación y reflexión sobre los procesos de subordinación desde un lenguaje poético, que presupone creativamente un pasado común, al tiempo que expresa la identidad amerindia como algo esencial, que no se pierde a pesar de la modernidad y de la migración. Su valor performativo reside también en el efecto de lo unísono que producen la simultaneidad de los sonidos del siku y los gestos colectivos (como levantar los brazos al mismo tiempo) donde se actualiza el sentimiento y la fuerza del ser juntos (Mauss, 1991 [1925]).

Al no existir una expresión que unificara el sentir de los pueblos amerindios radicados en Buenos Aires, esta canción constituye el hito de un sentido de pertenencia conjunta, pero además el hecho de que sea una canción evidencia la relevancia de la música para los migrantes de los Andes centrales radicados en la capital. La idea de los cinco siglos revive desde una lectura cronotrópica un evento del pasado para transformarlo en fuerza aglutinadora en el presente, operando como el significante flotante ${ }^{10}$ (Laclau, 1998) desde el cual articular la diversidad.

10 Significante flotante refiere a un exceso semántico representando una totalidad ausente que es la unidad del pueblo, la cual es deseada pero nunca definitivamente lograda (Laclau, 1998). 
En las fiestas de los Andes centrales -origen de quienes conducen esta manifestación (qollas, aymaras y quechuas)- los músicos se trasladan mientras tocan, acción que se denomina pasacalle ${ }^{11}$. Esta circunstancia se emparente con la marcha en tanto expresión de desplazamiento. De esta manera, para las y los migrantes de los Andes centrales y sus descendientes, marchar en la ciudad se asemeja a la forma de desplazarse cuando participan como músicos o danzantes en sus festividades tradicionales.

La perfomance de la marcha actualiza una forma de hacer política que presupone conexiones con la expresión propia de los Andes centrales. De esta forma, la ejecución colectiva del siku en esta marcha, deviene arte político en este mismo marco de interpretación.

\section{III) Santiago: desde la política del blanqueamiento a la configuración identitaria amerindia}

En Santiago de Chile, la marcha conmemorativa del 12 de octubre se realiza por primera vez en 1991. Quien fuera uno de sus organizadores, José Segovia, apodado Patara, afro aymara de Arica y poeta fundador del grupo musical Arak Pacha, nos señala que la elección de la fecha a conmemorar se debió a la necesidad de sensibilizar a la sociedad civil respecto a los 500 años de conquista. Para él, rememorar un año antes la fecha permitía afianzar la preparación de una plataforma de lucha conjunta en torno a una serie de derechos indígenas.

Organizamos la marcha del 12 de octubre en 1991 para que la gente se enterara de lo que venía el 92, las conmemoración de los 500 años de conquista, y nos pareció importante hacer algo en Santiago donde pareciera que no hubieran amerindios (Patara, 2015, p. 3-4).

En esta ocasión, quienes mayoritariamente participaron fueron organizaciones de música y danza andina, todas residentes en la capital, destacando la participación de la agrupación musical Manka Saya, conjunto de lakitas cuyo director es de la norteña ciudad de Iquique.

11 Término de origen español que invoca danza y música en movimiento cuyo fin es celebrar un evento especial desplazándose por las calles de un punto $\mathrm{A}$ a un punto $\mathrm{B}$. 
La actividad constó de un recorrido hacia el cerro Santa Lucía, y la realización de una ceremonia en una de las terrazas del cerro, llamada Caupolicán. La elección del lugar no es fortuita ya que se trata del cerro donde aparentemente Pedro de Valdivia habría fundado la ciudad, el cual es reivindicado tanto por organizaciones mapuche como andinas como un espacio sagrado precolonial de observación astronómica. En el mismo, actualmente se realizan actividades como el año nuevo amerindio, el willkakuti o inti raymi para aymaras o quechuas, y el wetripantu o wiñoltripantu para los mapuche.

En 1991 también se creó el Comité 500 años, encabezado por el difunto historiador Luis Vitale, para organizar la conmemoración de los 500 años de Conquista, como una forma de visibilizar demandas y reivindicaciones amerindias. A su vez, diversos colectivos afines a la demanda mapuche y pehuenche junto al grupo Tun, de danza y música aymara y mapuche, se coordinaron para movilizarse.

Los inicios de la década de los noventa es el período en que las recuperaciones de tierra en el sur del país se intensifican, a manos de la organización mapuche Consejo de Todas Las Tierras. Del mismo modo se crea la Ley Indígena y al año siguiente la Corporación Nacional de Desarrollo Indígena (CONADI), develando un proceso creciente de institucionalización.

A nivel internacional, el gobierno de Chile participa en la Exposición Universal de Sevilla de 1992 con la muestra de un Iceberg, un bloque gigante de hielo proveniente de la Antártida. Esta decisión generó mucha polémica, ya que a la vista de muchos chilenos representaba la frialdad, la lejanía, pero sobre todo la negación de lo amerindio como parte constitutiva de la identidad nacional.

En 1992, el Comité 500 años realizó una movilización que recorrió principalmente la calle peatonal Paseo Ahumada, desarrollándose una acción performática de la conquista, mediante la representación de la lucha entre españoles y mapuche. La mayoría de los asistentes eran personas no amerindias, cercanas a organizaciones de izquierda pero sobre todo de Derechos Humanos. También es la primera vez en que se realiza una acción contra un monumento de Pedro de Valdivia. A partir de ese momento, esta estatua sufre una serie de traslados, finalmente es dejado en un costado de la Plaza de Armas, frente a la Municipalidad de Santiago.

En cuanto a las organizaciones convocantes, desde 1992 la Coordinadora Mapuche Metropolitana se hará cargo de organizar año a año la marcha. A partir de ese momento hasta la actualidad se llamará la marcha mapuche, lo que generó que muchas 
organizaciones y personas amerindias no mapuche, como miembros de la Coordinadora Nacional Indianista (CONACIN), durante muchos años no participaran por sentirse excluidos.

Posteriormente, en 1995, la organización mapuche Meli Wixan Mapu, asume este rol, período en que la marcha se vuelve multitudinaria. Desde ese año comienzan a participar autoridades mapuche de comunidades en conflicto, posicionando demandas coyunturales, como por ejemplo la denuncia del asesinato de weichafes (guerreros) como Matías Catrileo o Alex Lemún, o el rechazo a la celebración del bicentenario de la República de Chile, con los doscientos años de la declaración de independencia en 2010.

Paralelamente, estos hechos van a coincidir con la reintegración de las agrupaciones de música y danza andina, consolidándose, desde aproximadamente 2010, el llamado Bloque Andino. En este espacio destaca la representación de la danza folclórica boliviana, el tinku, que debe su origen al ritual del mismo nombre que se realiza en el norte de Potosí durante la festividad de la Chakana o Cruz del Sur, a principios de mayo, correspondiendo al encuentro entre dos comunidades o parcialidades de un pueblo mediante la realización de una serie de combates rituales. Los movimientos que se despliegan en este contexto luego fueron resignificados por folcloristas como pasos de una danza de proyección, y dan cuenta de lo que hoy conocemos como tinku (Fernández y Fernández, 2015).

Algunos danzantes como Cristian Waman, fundador del grupo de danza Fraternidad Ayllu, señala que es a partir del 2000 en que danzas como el tinku, se hace presente en la movilización.

El tinku es una danza guerrera, representativa de una ceremonia que se hace al norte de Potosí, que calza con la energía que se quiere instalar en la marcha del 12 de octubre, de lucha por los derechos de los pueblos indígenas y de la búsqueda del encuentro entre diversos pueblos y organizaciones (Cristian Waman, 2011).

Durante todos esos años la marcha comenzó en Plaza Italia, lugar considerado como el epicentro de la movilización pero también de la ciudad (y a su vez de la planificación urbana), y finalizó en la terraza Caupolicán del cerro Santa Lucía. Sin embargo, en un momento dado, el entonces alcalde de Santiago, Jaime Ravinet, prohíbe su realización en el mismo cerro, por lo que los organizadores optan por finalizar la marcha con una ceremonia en los pies del mismo, en la Plaza Benjamín Vicuña, contando con la realización de un acto final, en que diversos voceros exponen los conflictos de las comunidades 
mapuche, además de realizarse una ceremonia y un purrum (danza) colectivo (Taypi Aru, 2011).

Desde el año 2011 la organización Meli Wixan Mapu genera un nuevo cambio, la marcha, debido a su masividad, modifica su recorrido finalizando en las inmediaciones del Museo de Arte Contemporáneo, en el Parque forestal, pasando, eso sí, tal como se hacía hasta este entonces, por el cerro Santa Lucía, a modo de rememoranza del origen y la continuidad de la misma. En este espacio, actualmente se desarrolla una feria de organizaciones y productos amerindios.

Este cambio provocó que la marcha finalice con incidentes entre manifestantes y carabineros, lo que antes, en las inmediaciones del cerro, no acontecía o si sucedía eran hechos aislados y controlados por las propias personas de la organización.

Para las organizaciones de música y danza andina, el año 2009 se dio un hito, por primera vez se marchó como bloque andino, el cual antes había sido parte de la Coordinadora Carnavalera de Santiago, donde además participaban otras agrupaciones como la Escuela Chinchintirapié. En este bloque se podían ver danzas como el tinku, el wayno, personajes como kusillos, todas acompañadas tanto por instrumentos de caña, como lakitas, como por bandas de bronce. Posteriormente desapareció la Coordinadora Carnavalera, creándose la Coordinadora Andina, la cual agrupó exclusivamente a grupos de danza y música de los Andes centrales. Esta coordinadora deja de existir, sin embargo el Bloque Andino persiste y se mantiene con mucho protagonismo dentro de la marcha.

En este proceso de empoderamiento del Bloque Andino podemos ver el despliegue y la resignificación de una memoria histórica que sitúa a la ciudad de Santiago como un espacio pluricultural, donde lo andino tiene cabida, a través de una serie de acciones conmemorativas, como por ejemplo la realización de una serie de festividades aymaras y quechuas, tanto del norte de Chile como de Bolivia y Perú, pero también mediante el desarrollo de la marcha del 12 de octubre.

En este contexto se entiende lo conmemorativo como toda práctica que coloca y configura una memoria compartida, que es fijada espacial y temporalmente en objetos, sujetos, fechas y lugares, mediante un conjunto de acciones que organizan y reproducen una memoria a instalar (Escobar y Fernández, 2008).

Por ello podemos decir que la marcha analizada es de tipo conmemorativa, ya que instala en un momento determinado del año, una memoria amerindia negada e invisibilizada 
sistemáticamente por parte del estado chileno, que a su vez opera como significante flotante (Laclau, 2008), en tanto establece un sentido compartido por parte de quienes marchan, de romper con el espacio discursivo de lo monocultural, fijando otras posibilidades identitarias, como la amerindia.

Con el tiempo, la conmemoración se ha ido replicando en otras ciudades de Chile, como Arica, Iquique, Temuco y Valdivia, aunque de manera más intermitente pero desde el mismo carácter de denuncia y reivindicación de un conjunto de demandas amerindias, además de integrarse elementos coyunturales y locales según la zona. Sin embargo la marcha realizada en Santiago seguirá siendo la más preponderante tanto por su masividad como por su constancia.

\section{IV) 25 años marchando. Análisis comparativo entre Buenos Aires y Santiago}

Con el propósito de profundizar en la reflexión sobre esta marcha y las significaciones del 12 de octubre en ambos lados de la cordillera de los Andes, presentaremos a continuación un análisis comparativo entre Buenos Aires y Santiago de Chile. En éste, tuvimos en cuenta los siguientes ejes: protagonistas, presencia de músicos y/o danzantes, volumen y territorio, demandas, clima, y relevancia socio-política y cultural. Consideramos que los mismos, representan los ítems fundamentales, por un lado para describir esta marcha y por otro para comprender semejanzas -en las cuales se sostiene nuestra hipótesis permitiendo esgrimir un argumento sólido- y diferencias, las cuales dan cuenta de las particularidades de cada ciudad y cada país: su gimnasia política en términos generales, su forma de marchar, el rol del arte en las marchas, la relación con la policía, las implicancias, vínculos y relaciones de las organizaciones amerindias, entre otras.

\section{1) Protagonistas}

En Buenos Aires esta marcha tiene como particularidad ser la única marcha anual protagonizada por amerindios. Qollas, considerados sus iniciadores, aymaras y quechuas de Bolivia y en menor medida del Perú, además de sus descendientes porteño-bonaerenses y miembros de otros pueblos: diaguitas, guaraníes, qom, mapuches y wichís. Una de las 
características que ha ido paulatinamente tomado esta marcha, es la diversificación de los participantes, puesto que se han ido incorporando nuevas agrupaciones amerindias y sobre todo un número cada vez mayor de personas no amerindios, muchos de ellos como músicos sikuris.

En Santiago, en tanto, la marcha es protagonizada sobre todo por organizaciones mapuche urbanas y algunas de zonas rurales, que visitan la ciudad para la ocasión. Destaca la participación de personas provenientes de organizaciones de Derechos Humanos, hinchadas de fútbol (de Colo Colo y de la Universidad de Chile), danzantes y músicos del Bloque Andino, entre otras colectividades.

\section{2) Presencia de músicos y/o danzantes.}

En Buenos Aires, desde 1991 tuvieron gran protagonismo en la participación los intérpretes de música autóctona, particularmente los sikuris, en su mayoría inmigrantes del noroeste argentino y de Bolivia, o hijos o nietos de éstos nacidos en Buenos Aires.

Según los antecedentes revisados, ésta sería la primera marcha protagonizada por músicos en Buenos Aires, los cuales además interpretan instrumentos autóctonos. En la ciudad, es usual que se presenten músicos en las marchas, pero no que éstos sean los protagonistas o quienes lideran la formación. En general, particularmente en las manifestaciones gremiales o aquellas convocadas por partidos o movimientos políticos, se ejecutan percusiones (bombo de batucada y redoblante preferentemente) acompañando a los marchistas.

En cambio en Santiago, sobre todo desde el Bloque Andino, el mayor protagonismo lo poseen las colectividades de danzas, que de igual forma se acompañan de músicos. En este caso, la puesta en escena de diversas danzas andinas rompe con la hegemonía estética criolla ("blanqueada") de uniformización, mediante el uso de vestimentas, sonoridades y colores vinculados a los pueblos amerindios. Lo mismo sucede para el caso mapuche, sin embargo quienes ejecutan las danzas son los propios mapuche, a diferencia del Bloque Andino con presencia mayoritaria de personas que no tienen vínculos de parentesco directo con los Andes centrales. 


\section{3) Volumen y territorio}

En Buenos Aires, ciudad con un consolidado ejercicio ciudadano de marchar, se trata de un evento acotado. Desde 1993, el contra-festejo del 12 de octubre se concentra y finaliza en la Plaza de los Dos Congresos, siendo una de las pocas marchas que comienza y termina en el mismo lugar. Pasándolo por el emblemático Obelisco, el desplazamiento es de aproximadamente 20 cuadras.

En Santiago, hasta mediados de los noventa, la marcha se iniciaba en Plaza Italia, recorriendo la Alameda Bernardo O'Higgins para finalizar en las faldas del cerro Santa Lucía y luego dirigirse a su cima. Posteriormente se prohibió el acceso al cerro pero se mantuvo el acto final a sus pies. Todavía comienza en Plaza Italia, pero desde hace algunos años, luego de pasar el cerro Santa Lucía, se dirige por calle Miraflores para finalizar en el Parque Forestal, detrás del Museo de Arte Contemporáneo.

A diferencia del caso argentino, la marcha mantiene su masividad, aumentando año a año. Se calcula una asistencia en promedio de diez mil personas.

\section{4) Demandas}

En Buenos Aires, en general, en esta marcha no se suelen vehiculizar otras demandas políticas coyunturales, las cuales han tendido a tener su propio espacio, con la realización de manifestaciones concretas para esos fines. Es así que ante demandas específicas, se optó por ejemplo por hacer escraches al Instituto Nacional de Asuntos Indígenas (INAI), a las casas de provincias del NEA (Noreste Argentino), o al diario Clarín por injurias o actos discriminatorios -p.e.agravios a Evo Morales. Así como actualmente movilizaciones en apoyo al pueblo qom o por demandas por territorios ancestrales querandíes, y otras por reclamos medioambientales, como contra la empresa Monsanto o la megaminería.

De esta forma, la marcha porteña del 12 de octubre es el lugar de un reclamo unificador y englobante. Allí se reivindica la lucha amerindia o de los pueblos del Abya Yala en general, con la participación de distintas pertenencias -en una ciudad de alta concentración migratoria, tanto interna como internacional- y con un discurso reivindicativo basado en la diversidad de pueblos con propósitos políticos similares. 
En Santiago en cambio, año a año, se posicionan demandas coyunturales, sobre todo del pueblo mapuche, en torno al asesinato de algunos de sus dirigentes, o en contra del bicentenario de Chile, o visibilizando los principales conflictos de las comunidades mapuche más criminalizadas durante el año. Es así que todos los años se levanta una demanda en particular, en medio de la mantención de demandas históricas, como el reconocimiento de autonomía y territorio de los pueblos amerindios. Por otra parte, poco a poco se ha visibilizando también la situación de los pueblos amerindios que fueron exterminados por el Estado chileno, como los selk'nam, mediante carteles y diversas perfomances.

\section{5) Clima}

Mientras en Buenos Aires ha tendido a ser pacífica, sobre todo desde el kichnerismo en adelante, donde tras la masacre del Puente Pueyrredón (2002) se sistematizó una política de no represión policial ${ }^{12}$. En Santiago de Chile, al igual que la marcha del 11 de septiembre, y acorde a una gimnasia política que se remonta a la dictadura, la misma termina con enfrentamientos con carabineros ${ }^{13}$. Así, esta marcha, al igual que la mayoría de las manifestaciones masivas, finaliza con la intervención policial y una fuerte represión.

\section{6) Relevancia socio-política y cultural.}

En ambas ciudades el 12 de octubre es, probablemente, la tercera marcha conmemorativa más relevante después del 1 de mayo y del día de inicio de la última dictadura (24 de marzo en Argentina y 11 de septiembre en Chile). A diferencia de las dos primeras, en las dos metrópolis la misma es celebrada en clave festiva, siendo protagonistas músicos y/o danzantes.

En síntesis, la fecha político-simbólica del 12 de octubre ha ido configurando el espacio socio-territorial de estas metrópolis con formas alternativas de conectar sitios (articulando protestas y reclamos) pero también con la habilitación de nuevos lugares de encuentro y

\footnotetext{
12 Pese a que en Argentina el actual gobierno de derecha de Mauricio Macri, en el poder desde diciembre de 2015, ha instaurado una política de represión policial en las marchas, en 2016, la misma no fue reprimida.

13 Nombre de la policía chilena.
} 
de acción. En el espacio social urbano de Buenos Aires y Santiago se fueron inscribiendo memorias denunciantes de las historias hegemónicas, proyectos reivindicatorios desde la preexistencia compartida a los estados-nacionales, y formas de arte político conectadas con la trama que esta marcha fue ayudando a gestar.

A continuación se presenta un cuadro resumen con los ejes analizados.

\section{BUENOS AIRES}

-Migrantes internos (guaraníes qollas, qom, mapuches, wichís) e internacionales (aymaras y quechuas)

Protagonistas

Volumen

Territorio

Expresión artística

Demanda

Condición

Relevancia socio-política y cultural con aumento de locales con el paulatino proceso de maduración de la marcha -Músicos

-Activistas políticos

-Primeras dos marchas muy masivas (en 1992, entre nueve y veinte mil personas) disminuyendo su flujo desde 1993 para mantenerse estable

Céntrica con desplazamiento acotado

Presencia musical del instrumento siku exclusivamente. Sonoridad al unísono (con particular énfasis en la canción "cinco siglos")

Genérica, sobresale el tema de la conquista y la colonización y los cinco siglos encima de cuestiones coyunturales

Pacífica, sin actos de violencia

Probablemente la tercera marcha conmemorativa más relevante después del 1 de mayo y del día de inicio de la última dictadura. A diferencia de las dos primeras es celebrada en "clave festiva"

\section{SANTIAGO}

-locales (mapuches, conocida como la "marcha mapuche"; "blancos" y "mestizos", connotada presencia de universitarios)

-Migrantes internos (mapuches y aymaras)

-Activistas políticos

-Músicos y danzantes

-Primeras marchas muy pequeñas, aumentando su volumen a medida que pasa el tiempo

-Actualmente diez mil o más personas Céntrica con desplazamiento que se ha ido ampliando con los años

Múltiples expresiones artístico

culturales (origen tinku en el año 2000)

Coyuntural (asesinados, demandas concretas de tierras) por sobre el tema de la conquista y colonización Pacífica al comienzo, terminando con enfrentamientos con la policía (carro hidrante y bombas lacrimógenas) 


\section{Comentarios a modo de cierre}

Las culturas amerindias desde el siglo XV compartieron un destino de dolor pero al mismo tiempo de resistencia. El proceso histórico de subalternización paulatinamente fue posicionando a los diversos grupos en una lucha común, quienes comenzaron a demandar ya no sólo ciertas garantías (tierras, subsidios, etc.) sino reivindicación de usos y costumbres propias, soberanía, reconocimiento y participación política, que se expresan y visibilizan cada 12 de octubre (Briones, 1998).

La conformación y consolidación de una marcha ininterrumpida desde hace un cuarto de siglo en dos capitales imaginadas como "blancas" y alejadas de la efeméride que sintetiza el "descubrimiento" de América, presume asombro a su vez que pareciera ser justamente dicha condición la que otorga sentido a una marcha conmemorativa de forma permanente.

Por su parte, su celebración en clave festiva y en desplazamiento (pasacalle), de forma similar a como acontece en las festividades propias de los Andes centrales, presupone su principal particularidad. Así, en el marco de la conmemoración de la conquista de América, la perfomance de la marcha en Buenos Aires y Santiago actualiza una forma de hacer política que presupone conexiones con aquellas de los Andes centrales, donde suele haber un estrecho vínculo entre la práctica política y la artística, principalmente a través de su manifestación dancística-musical. La ejecución colectiva en la marcha del 12 de octubre, deviene arte político en este mismo marco de interpretación. Los testimonios recogidos coinciden en identificar a la música y la danza como un espacio de resistencia, y al músico y el danzante como un sujeto con capital social valorado.

En síntesis, la elección del lenguaje musical y dancístico, permite actualizar los sentidos -todavía en emergencia y estructurados desde el sentir- de un ser juntos (Mauss, 1991 [1925]) que no tenía más definición que el "ser preexistentes a los estados-nación".

Desde comienzos de la última década del siglo XX, los quinientos años devino la fórmula expresiva de este contexto particular, uno en el que fueron emergiendo conceptos, nuevos sentidos, metáforas y relecturas de los procesos históricos y la formación de alteridades hegemónicas. Estos desplazamientos en las formaciones discursivas, en repudio a una efeméride orquestada desde la madre patria donde se conjeturó una iberoamericanidad como comunidad imaginada (Anderson, 1993), se fueron instalando en el discurso de líderes y representantes de los pueblos del Abya Yala. 
En el presente trabajo intentamos describir y analizar el devenir de esta marcha en el último cuarto de siglo en ambos lados del sur de la cordillera de los Andes. La idea fue configurar algunas conjeturas de cómo una marcha conmemorativa por la llegada de Colón al Caribe, a varios miles de kilómetros, se transformó en una de las principales marchas en ambas capitales- probablemente las más importantes después de la del 1 de mayo y de repudio al inicio de la última dictadura en ambos países.

Consideramos que, en gran medida, los aportes de esta investigación subyacen en nuestra condición de danzante y músico. El posicionarnos en la misma entre nuestro rol como investigadores sociales y sujetos-parte (Caicedo, 2003) nos llevó a comprometernos en un proceso de desmonopolización de la mirada (Rappaport, 2007). Para este fin fue central habernos dado cuenta que las reflexiones provocadas a partir de nuestra participación podían ser el lugar de una antropología comprometida, donde cuestionamos la falsa dicotomía entre la rigurosidad académica y el compromiso con la comunidad (Hernández Castillo, 2006).

$\mathrm{Al}$ redefinir de este modo el diseño metodológico de nuestra investigación conjunta, nos fuimos posicionando como actores sociales en un proyecto descolonizador donde los propósitos del grupo con los que participamos y los nuestros como investigadores, si bien diferentes, son, sobre todo, congruentes. Entendemos esta coherencia bajo la lógica de que el rol de la antropología latinoamericana actual debe ser la de otorgar a los pueblos amerindios y otros grupos subalterizados, los datos e interpretaciones que la antropología como ciencia colonial ha pretendido durante mucho tiempo reservar exclusivamente para los investigadores (Hale, 2005).

Hoy en día, tanto en Buenos Aires como en Santiago, el 12 de octubre habilita una lectura interpretativa desde la cual fue y es posible conectar las experiencias del pasado con las del presente. En este proceso se objetiva una arena de disputas donde distintos sectores sociales -anclados en reconstrucciones históricas disímiles sobre la colonización- fueron estableciendo contiendas diversas en torno a los derechos amerindios, los modos de inclusión-exclusión en proyectos estadonacionales y los reclamos de reparación histórica.

En ambas ciudades la marcha del 12 de octubre se instala como un evento cronotrópico que fue permitiendo posicionar la noción de identidades amerindias y sus usos políticos en la construcción del presente (Isla, 2003). El valor simbólico de una fecha común reside en la construcción cronotrópica de una historia compartida, mientras que el valor político en la habilitación de un nuevo lugar de enunciación desde el cual dar a conocer demandas similares y una nueva subjetividad política con mayor fuerza para 
perseguir metas en temas de reconocimientos de derechos. Dicho proceso colaboró en la visibilización de los diversos pueblos amerindios, a través de la música y la danza como principales repertorios culturales.

La selección de una fecha única, habilitó estratégicamente una demanda política, permitiendo el surgimiento de un nuevo actor social protagónico en la región, el cual vio, en el año 1992, la posibilidad de representar una idea de despertar y cambio, incubada desde hacía décadas por algunos líderes y desde hacía mucho más tiempo por la memoria de estos pueblos.

La misma, protagonizada por danzantes músicos en Buenos Aires y Santiago, fue un acontecimiento que contribuyó en la constitución de una nueva forma amerindia de hacer política, la cual esboza que la linealidad 'trágica' y uniforme que ha atravesado el destino de los pueblos del Abya Yala desde Colón hasta la actualidad, podría cortarse.

En esta última dirección, es que esperamos haber dado profundidad y complejidad a un proceso que, hoy en día, podemos valorar como creador de marcos interpretativos, habilitador de lugares sociales colectivos y producto de formas novedosas de intervenir en el campo político.

\section{Referencias}

Anderson, B. (1993). Comunidades imaginadas. Reflexiones sobre el origen y la difusión del nacionalismo. México DF, México: Fondo de Cultural Económica.

Barragán, F. (2003). La ejecución y enseñanza de los instrumentos étnicos cómo recuperación de la identidad. Buenos Aires, Argentina: Consejo Argentino de la Música (CAMU).

Barragán, F. y Mardones, P. (2012). CHE SIKURI. La expresión del siku en el contexto porteño. Santiago, Chile: III Congreso Latinoamericano de Antropología.

Bengoa, J. (2000). La Emergencia Indígena. Santiago, Chile: Fondo de Cultura Económica.

Bengoa, J. (2007). Chile mestizo. Revista Mensaje, 56 (564), 48-51. 
Briones, C. (1998). La alteridad del Cuarto Mundo. Una deconstrucción antropológica de la diferencia. Buenos Aires, Argentina: Ediciones Del Sol.

Bunge, M. (1992). Siglo XXI: ¿̨recolonización o integración? La cumbre del Quinto Centenario. Buenos Aires, Argentina: Suplemento Especial Revista Clarín. 23 de junio. Pág. 12-13.

Caicedo, A. (2003). Aproximaciones a una antropología reflexiva. Tábula Rasa, 1, 165-181.

Drago, T. (1992). La decisión de 21 Estados. La cumbre del Quinto Centenario. Buenos Aires, Argentina: Suplemento Especial Revista Clarín. 23 de junio. Pág. 18-19.

Escobar,M.yFernández,R.(2008).Performatividad,memoriayconmemoración:la experiencia de la marchaRearme en el Chile post-dictadorial. ForumQualitativeSozialforschung / Forum: Qualitative Social Research, 9 (2), Art. 36.

Exposición Universal de Sevilla (1992). Página de la Exposición universal realizada en Sevilla en 1992, La Era de los descubrimientos. Recuperado en http://www.expo92.es/laexpo/ index.php?seccion $=$ cifras

Fernández, F. y Fernández, R. (2015).El tinku como expresión política: Contribuciones hacia una ciudadanía activista en Santiago de Chile. Revista Psicoperspectivas, 14 (2), 62 71.

Gala, Antonio (1992). Las democracias de papel. La cumbre del Quinto Centenario. Buenos Aires, Argentina: Suplemento Especial Revista Clarín. 23 de junio. Pág. 16-17.

Grimson, A. (2005). Lo que no entra en el crisol - Inmigración boliviana, comunicación intercultural y procesos identitarios. Buenos Aires, Argentina: Prometeo Libros.

Instituto Nacional de Estadísticas y Censos (INDEC) de la República Argentina (2010). Censo Nacional. Auto-reconocimiento indigena en Buenos Aires. Recuperado en http://www. censo2010.indec.gov.ar/

Isla, A. (2003). Los usos políticos de la memoria y la identidad. Estudios Atacameños, 26, 3544.

Hale, Ch. (2004, enero, 20). Reflexiones hacia la Práctica de una Investigación Descolonizada. En el III Seminario de Trabajo del Proyecto "Gobernar en la diversidad". Managua: CIESAS. 
Hernández Castillo, A. (2006). ¿Conocimiento para qué? Antropología Socialmente comprometida: entre las resistencias locales y los poderes globales. Chiapas, México: CIESAS.

Herrera de Noble, E. (1992). Las demandas del fin de siglo. La cumbre del Quinto Centenario. Buenos Aires, Argentina: Suplemento Especial Revista Clarín. 23 de junio. Pág. 4.

Huergo, H. (1992). Iberoamérica, verde y competitiva. La cumbre del Quinto Centenario. Buenos Aires, Argentina: Suplemento Especial Revista Clarín. 23 de junio. Pág. 26-27.

Lohlé, J. P. (1992). De Guadalajara a Madrid. La cumbre del Quinto Centenario. Buenos Aires, Argentina: Suplemento Especial Revista Clarín. 23 de junio. Pág. 10.

Mauss, Marcel (1991 [1925]). Ensayo sobre el don. La forma y la razón del intercambio en las sociedades arcaicas. Madrid, España: Editorial Tecnos.

Mires, F. (1992). El discurso de la indianidad. Quito, Ecuador: Editorial AbyaYala.

Naishtat, S. (1992). ¿España abre la puerta de Europa? La cumbre del Quinto Centenario. Buenos Aires, Argentina: Suplemento Especial Revista Clarín. 23 de junio. Pág. 14.

Piñeiro, M. (1992). Palanca de la tercera revolución tecnológica. La cumbre del Quinto Centenario. Buenos Aires, Argentina: Suplemento Especial Revista Clarín. 23 de junio. Pág. 22-23.

Proyecto Filosofía en español (Sin fecha). «Fiesta de la Raza» | «Día de la Raza». Recuperado en http://www.filosofia.org/ave/001/a220.htm

Rappaport, J. (2007). Más allá de la escritura: La epistemología de la etnografía en colaboración. Washington, Estados Unidos: Georgetown University.

Rivera Cusicanqui, S. (2013, abril, 29). Entrevista realizada por los graduados de la Facultad de Filosofía y Letras de la Universidad Austral de Chile (FFHH UACh). Recuperado en http://vimeo.com/65071028

Santos, M. (2012). Repertorios culturales y estrategias de acción. Reflexiones desde la perspectiva de la cultura en movimiento. Debates en Sociología, 37, 155-168. 
Sebreli, J. J. (1991). El asedio a la modernidad. Buenos Aires, Argentina: Editorial Sudamericana.

Trouilot, M. R. (1995). Silencing the Past: Power and the Production of History. Beacon Press.

Tamagno, L. (1991). La cuestión indígena en Argentina y los censores de indianidad. América Indígena, 1, 123-152.

Taypi Aru (2011). Santiago Jacha Marka. Danzas, cosmovisión, festividades y acción política en el espacio urbano. Santiago, Chile: Editorial Quimantú.

Vitale, L. (1992). Historia de nuestra América II. 500 años de resistencia indígena. Santiago, Chile: Ediciones CELA (Centro de Estudios Latinoamericanos).

Vizcarra, Z. D. (1944). Origen del nombre, concepto y fiesta de la Hispanidad. Madrid, España: Semanario “El español”. Año III, No 102.

Yáñez Barnuevo, L. (1992). El año mágico de 1992. La cumbre del Quinto Centenario. Buenos Aires, Argentina: Suplemento Especial Revista Clarín. 23 de junio. Pág. 6.

\section{Referencias Primarias}

\section{Buenos Aires}

Lenton, D. (26 de octubre de 2013). Entrevista no grabada (reconstrucción a base de notas). Cuaderno 2, Página 8 y 24. Capital Federal, Buenos Aires. Registro: Pablo Mardones.

Barrera, P. (13 de octubre de 2016). Entrevista no grabada (reconstrucción a base de notas). Cuaderno 5, Página 1. Capital Federal, Buenos Aires. Registro: Pablo Mardones.

Barragán, F. (16 de diciembre de 2014). Entrevista no grabada (reconstrucción a base de notas). Cuaderno 4, Página 18. Capital Federal, Buenos Aires. Registro: Pablo Mardones. Romero, L. (9 de diciembre de 2016). Entrevista no grabada (reconstrucción a base de notas). Cuaderno 5, Página 2. Capital Federal, Buenos Aires. Registro: Pablo Mardones.

Villanueva, W. (13 de noviembre de 2014). Entrevista no grabada (reconstrucción a base de notas). Cuaderno 4, Página 3, 5 y 9. Capital Federal, Buenos Aires. Registro: Pablo Mardones. 
Santiago

Waman, C. (12 de junio de 2011). Entrevista no grabada (reconstrucción a base de notas). Cuaderno 1, Página 2. Santiago de Chile. Registro: Francisca Fernández

Segovia, J. (Patara) (03 de marzo de 2015). Entrevista no grabada (reconstrucción a base de notas). Cuaderno 4, Página 3 y 4 . Santiago de Chile. Registro: Francisca Fernández 